\title{
Workplace standing time and the incidence of obesity and type 2 diabetes: a longitudinal study in adults
}

Jean-Philippe Chaput $^{1 *}$, Travis J Saunders ${ }^{2}$, Mark S Tremblay ${ }^{1}$, Peter T Katzmarzyk ${ }^{3}$, Angelo Tremblay ${ }^{4}$ and Claude Bouchard ${ }^{5}$

\begin{abstract}
Background: It is increasingly recognized that standing represents a simple solution to extended periods of sitting. However, it is currently unknown whether workplace standing time is prospectively associated with a lower incidence of chronic diseases. The objective of this study was to examine the association between workplace standing time and the incidence of overweight/obesity (OW/OB) and impaired glucose tolerance/type 2 diabetes (IGT/T2D) in adults.
\end{abstract}

Methods: A longitudinal analysis from the Quebec Family Study (Canada) was conducted on 293 participants, aged 18 to 65 years, followed for a mean of 6 years. Information on self-reported occupational standing time as well as several covariates was collected at both baseline and follow-up. Outcome measures included the development of OW/OB (i.e. body mass index $\geq 25 \mathrm{~kg} / \mathrm{m}^{2}$ ) and IGT/T2D (i.e. 2 -h postload plasma glucose level $\geq 7.8 \mathrm{mmol} / \mathrm{L}$ ).

Results: The incidence rates of OW/OB and IGT/T2D over the 6-year follow-up period were $17.4 \%$ and $12.6 \%$, respectively. Significant negative associations were observed between the amount of occupational standing time and the development of outcome measures. However, the associations were no longer significant after adjustment for age, sex, smoking habits, total annual family income, daily caloric intake, and submaximal working capacity. In age- and sex-adjusted logistic regression analysis, significant negative linear trends were observed across levels of standing time and the outcome variables. However, the associations were no longer significant after further adjustment for the other covariates. Finally, we observed that the change in standing time from baseline to year 6 was significantly associated with the development of outcome measures, with higher incidence rates in adults reporting a reduction in standing time at follow-up. However, the associations became non-significant after adjustment for covariates.

Conclusions: Greater occupational standing time is not sufficient in and of itself to prevent the development of $\mathrm{OW} / \mathrm{OB}$ and IGT/T2D in adults. Future efforts are needed to better understand the potential benefits of higher amounts of standing time throughout the day on the prevention of chronic diseases.

Keywords: Standing, Sitting, Obesity, Diabetes, Longitudinal study, Adults

\footnotetext{
*Correspondence: jpchaput@cheo.on.ca

'Healthy Active Living and Obesity Research Group, Children's Hospital of Eastern Ontario Research Institute, 401 Smyth Road, Ottawa, ON K1H 8L1, Canada

Full list of author information is available at the end of the article
} 


\section{Background}

Accumulating evidence associates sedentary behavior (e.g. sitting) with adverse health outcomes including obesity and type 2 diabetes [1-5]. Studies also suggest that the effects of sedentary behavior on health indicators may be independent of moderate-to-vigorous physical activity [6-8]. However, many low-energy-expenditure activities can be classified as "sedentary behaviors" (e.g. reading, television viewing, driving) with effects that may be different on health indicators depending on the specific behavior [9-12]. Among behaviors at the low end of the energy expenditure continuum, standing has not received much attention in its ability to prevent the development of adverse health outcomes.

Breaking up sedentary time has recently been shown to be promising for improving cardiometabolic health [13-18]. One of the easiest ways to interrupt prolonged sitting is to stand up. Although standing quietly involves low levels of energy expenditure (approximately 1.2 METs), it engages a large muscle mass in the lower extremities and may represent a healthier alternative to sitting. Interestingly, a recent study reported that greater time spent standing was associated with a lower risk of mortality in adults [19]. Small-scale intervention studies also suggest that replacing workplace sitting with standing may reduce the glycemic response to a test meal $[20,21]$. However, it is unknown whether workplace standing time is prospectively related to a lower incidence of chronic diseases. Given that standing represents a simple solution to reduce extended periods of sitting, it is of interest to understand the association between standing and cardiometabolic health.

Therefore, the objective of this study was to examine the association between occupational standing time and the incidence of overweight/obesity (OW/OB) and impaired glucose tolerance/type 2 diabetes (IGT/T2D) in adults. We hypothesized that greater amounts of standing would be related to a lower incidence of the abovementioned outcome measures.

\section{Methods}

\section{Participants}

The Quebec Family Study was initiated at Laval University in 1978 . The primary objective of this study was to investigate the genetics of fitness, body composition and cardiovascular risk factors. In phase 1 of the study (1979 to 1982), a total of 1650 individuals from 375 families (nuclear families with biological or adopted offspring, pairs of twins of both types, and uncle/aunt and nephew and niece when available) were recruited and assessed. Recruitment was conducted irrespective of body weight during phase 1 , resulting in a cohort with a wide range of body mass index levels. In phase 2 (1989-1997) and 3 (1998-2002), 100 families from phase 1 were retested, and an additional 123 families with at least 1 parent and 1 offspring with a body mass index of $32 \mathrm{~kg} / \mathrm{m}^{2}$ or higher were added to the cohort. Families were all of French descent and were living for the most part within $80 \mathrm{~km}$ of Quebec City (Canada). Details on recruitment procedures and other aspects of the Quebec Family Study can be found elsewhere [22,23]. This cohort thus represents a mixture of random sampling and ascertainment through obese individuals. The present analyses are based on participants tested in phases 2 and 3 because some measurements were not available in phase 1 . Adults between 18 and 65 years of age were selected for longitudinal analyses $(n=293)$. A total of 23 participants were excluded because they were outside this age range. The mean duration of follow-up between phase 2 and 3 was $6.0 \pm 0.9$ years. All subjects provided written informed consent to participate in the study. The project was approved by the Medical Ethics Committee of Laval University.

\section{Standing time assessment}

To assess the primary exposure variable, participants completed a questionnaire and answered the following question: "How much time do you spend standing during your main occupation (e.g. at work)?" Responses included ( $i$ ) all the time, (ii) most of the time, (iii) half of the time, and (iv) rarely/never. The assessment was performed at both baseline and after 6 years.

\section{Assessment of outcome variables Overweight/obesity (OW/OB)}

At both baseline and year 6, height was measured to the nearest $0.1 \mathrm{~cm}$ using a stadiometer, and body weight was measured to the nearest $0.1 \mathrm{~kg}$ using a digital panel indicator scale (Beckman Industrial Ltd, Model 610/612, Scotland, UK). Body mass index (BMI) was calculated as body weight divided by height squared $\left(\mathrm{kg} / \mathrm{m}^{2}\right)$. OW/OB was defined as a BMI $\geq 25 \mathrm{~kg} / \mathrm{m}^{2}$, in agreement with well-established international standards [24]. OW/OB were combined in the analyses due to the low incidence of $\mathrm{OB}$ alone.

\section{Impaired glucose tolerance/type 2 diabetes (IGT/T2D)}

A $75 \mathrm{~g}$ oral glucose tolerance test was performed in the morning after a 12-h overnight fast. Blood samples were collected in tubes containing EDTA and Trasylol (Miles Pharmaceutics, Rexdale, ON, Canada) through a venous catheter from an antecubital vein at $-15,0,15,30$, $45,60,90,120,150$ and $180 \mathrm{~min}$. Plasma glucose concentration was measured enzymatically [25], and fasting glucose concentration was calculated as the mean of the -15 and 0 min concentrations. T2D and IGT were defined according to the American Diabetes Association and the World Health Organization criteria [26,27]. T2D was defined as use of insulin or a hypoglycemic agent, a 
fasting plasma glucose level of $126 \mathrm{mg} / \mathrm{dL}$ or more ( $\geq 7.0 \mathrm{mmol} / \mathrm{L}$ ), or a 2 -h postload plasma glucose level of $200 \mathrm{mg} / \mathrm{dL}$ or more $(\geq 11.1 \mathrm{mmol} / \mathrm{L})$. On the other hand, IGT was defined as a 2-h postload plasma glucose level of $140 \mathrm{mg} / \mathrm{dL}$ or more $(\geq 7.8 \mathrm{mmol} / \mathrm{L})$ in participants not meeting the criteria for T2D. The measurements were performed the same way at both baseline and follow-up. Similar to OW/OB, we combined IGT and T2D cases.

\section{Covariates}

Numerous variables were measured via self-reported questionnaires at baseline and year 6 . These included age, sex, smoking habits (smoker or nonsmoker), and total annual family income (Canadian dollars per year). Additionally, daily energy intake ( $\mathrm{kcal} /$ day) was assessed with a 3-day food record (two week days and one weekend day). This method of dietary assessment has been shown to provide a reasonably reliable measurement of food intake in this population [28]. Finally, physical work capacity at a heart rate of $150 \mathrm{bpm}\left(\mathrm{PWC}_{150}\right)$, determined by a progressive exercise test on a modified Monark cycle ergometer, was used as an indicator of cardiorespiratory fitness, as previously described [29]. $\mathrm{PWC}_{150}$ is expressed in kilopond per minute per kilogram $(\mathrm{kpm} / \mathrm{kg})$ to take individual differences in body weight into account. These 6 covariates were chosen because of their association with the exposure and outcomes and on the basis of previous research $[1,2,17,19]$. Given that over-fitting can be a concern with our relatively small sample size, different analyses were conducted to assess model fit (including testing for multicollinearity) and results demonstrated that our models had good predictive performance and were not subject to over-fitting.

\section{Statistical analysis}

To determine if men and women could be combined, sex-by-standing time interactions were assessed for all dependent variables. No significant interactions were found, therefore data for both sexes were combined to maximize power. Baseline characteristics of participants by standing time category were compared by analysis of variance (continuous variables) or chi-squared test (categorical variables). Among participants free of the outcome of interest at baseline $(n=151$ normal weight and $n=260$ without IGT/T2D), the incidence of OW/ $\mathrm{OB}$ and IGT/T2D by standing time category over the 6 year follow-up period was calculated and a chi-squared test was used to assess statistical significance. Multivariable logistic regression analysis was also used to evaluate the risk for the development of OW/OB and IGT/T2D according to the amount of standing time. The category "rarely/never" was used as the reference group. The results from two models are presented: $(i)$ adjusted for age and sex and (ii) additionally adjusted for smoking habits, total annual family income, daily caloric intake, and submaximal working capacity. Odds ratios (OR) and 95\% confidence intervals (CI) were reported. Finally, a chi-squared test was used to compare the incidence of $\mathrm{OW} / \mathrm{OB}$ and IGT/T2D across categories of changes in standing time between baseline and year 6 (decreased, maintained, increased). Because some individuals in this study came from the same nuclear family and are biologically related, we adjusted for clustering in the analyses using the generalized estimating equations statistical method to avoid underestimation of standard deviations. This procedure allowed us to model standing time and covariates as repeated measures at two time points (baseline and 6 years later), thus taking into account both measures over time. A 2-tailed $P$ value of less than 0.05 was the threshold to indicate statistical significance. All statistical analyses were performed using JMP version 11 (SAS Institute, Cary, NC).

\section{Results}

Baseline characteristics of participants within each standing time group are shown in Table 1 . Among the 293 Caucasian participants of this study, 33\% reported standing rarely or never, $23 \%$ half of the time, $19 \%$ most of the time, and $25 \%$ all the time during their main occupation.

Over the 6-year follow-up period, 51 new cases of OW/OB (17.4\%) and 37 new cases of IGT/T2D (12.6\%) were observed (there were 151 normal weight participants and 260 without IGT/T2D at baseline). As shown in Figure 1, a negative dose-response association was observed between the amount of standing time and the development of OW/OB and IGT/T2D $(P<0.05)$. However, the associations were no longer significant after adjusting for covariates (age, sex, smoking habits, total annual family income, daily caloric intake, and submaximal working capacity) (data not shown). Specifically, total annual family income and submaximal working capacity were the main confounders of the relationship (data not shown).

The results of the multivariable logistic regression analysis assessing the relationship between standing time and the development of OW/OB and IGT/T2D are presented in Table 2 . In the age- and sex-adjusted analyses, there were significant negative linear trends across levels of standing time and the outcome variables. However, the associations were no longer significant after further adjustment for smoking habits, total annual family income, daily caloric intake and submaximal working capacity. Here again, the addition of total annual family income and submaximal working capacity to the models resulted to the greater attenuation of ORs (data not shown). Of note, the delta ORs between the "Rarely/ Never" standing group and the "All the time" standing 
Table 1 Baseline descriptive characteristics of participants across levels of standing time

\begin{tabular}{|c|c|c|c|c|c|}
\hline & $\begin{array}{l}\text { Rarely/Never } \\
(n=97)\end{array}$ & $\begin{array}{l}\text { Half of the time } \\
(n=66)\end{array}$ & $\begin{array}{l}\text { Most of the time } \\
(n=57)\end{array}$ & $\begin{array}{l}\text { All the time } \\
(n=73)\end{array}$ & $P$ \\
\hline Age (years) & $37.3 \pm 14.7$ & $42.2 \pm 13.7$ & $42.6 \pm 14.0$ & $35.6 \pm 12.2$ & $<0.01$ \\
\hline \multicolumn{6}{|l|}{ Sex } \\
\hline Men (\%) & 56 & 37 & 37 & 43 & \\
\hline Women (\%) & 44 & 63 & 63 & 57 & 0.04 \\
\hline Body mass index $\left(\mathrm{kg} / \mathrm{m}^{2}\right)$ & $25.7 \pm 5.5$ & $26.3 \pm 6.3$ & $25.1 \pm 4.5$ & $25.2 \pm 5.6$ & 0.61 \\
\hline Waist circumference (cm) & $85.0 \pm 14.9$ & $84.4 \pm 16.8$ & $82.2 \pm 12.6$ & $81.9 \pm 15.6$ & 0.53 \\
\hline \multicolumn{6}{|l|}{ Weight status ${ }^{\mathrm{a}}$} \\
\hline Normal weight (\%) & 50 & 52 & 58 & 59 & \\
\hline Overweight (\%) & 35 & 22 & 29 & 26 & \\
\hline Obese (\%) & 15 & 26 & 13 & 15 & 0.35 \\
\hline \multicolumn{6}{|l|}{ Diabetes status $^{\mathrm{b}}$} \\
\hline Normal (\%) & 84 & 76 & 81 & 95 & \\
\hline IGT (\%) & 10 & 20 & 14 & 3 & \\
\hline Type 2 diabetes (\%) & 6 & 4 & 5 & 2 & 0.08 \\
\hline \multicolumn{6}{|l|}{ Smoking habits } \\
\hline Nonsmoker (\%) & 84 & 87 & 85 & 79 & \\
\hline Smoker (\%) & 16 & 13 & 15 & 21 & 0.64 \\
\hline Total annual family income $(\$ C)$ & $66,848 \pm 26,846$ & $54,180 \pm 24,886$ & $52,700 \pm 21,740$ & $56,323 \pm 23,238$ & $<0.01$ \\
\hline Energy intake (kcal/day) & $2,329 \pm 634$ & $2,211 \pm 648$ & $2,226 \pm 647$ & $2,498 \pm 979$ & 0.11 \\
\hline $\mathrm{PWC}_{150}(\mathrm{kpm} / \mathrm{kg})$ & $9.3 \pm 2.9$ & $8.9 \pm 2.4$ & $8.5 \pm 3.6$ & $9.1 \pm 3.2$ & 0.68 \\
\hline
\end{tabular}

Values are presented as mean \pm SD for continuous variables and percentage (\%) for categorical variables. Statistical significance was assessed by analysis of

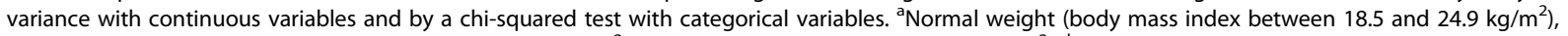
overweight (body mass index between 25.0 and $29.9 \mathrm{~kg} / \mathrm{m}^{2}$ ) and obese (body mass index $\geq 30 \mathrm{~kg} / \mathrm{m}^{2}$ ). ${ }^{\mathrm{b}}$ Type 2 diabetes and impaired glucose tolerance were defined according to the American Diabetes Association and the World Health Organization criteria [26,27]. Abbreviations: IGT impaired glucose tolerance; $P W C_{150}$ physical work capacity at a heart rate of $150 \mathrm{bpm}$.

group were reduced from a difference of 33\% (0.94 to 0.63 ) to $12 \%$ (0.97 to 0.85$)$ and from a difference of $27 \%$ (0.91 to 0.66 ) to $5 \%$ (0.96 to 0.91 ) for OW/OB and IGT/ T2D, respectively, after multivariable adjustment.

Finally, the incidence of OW/OB and IGT/T2D across categories of changes in standing time is shown in Figure 2. We observed that the change in standing time (from baseline to year 6) was significantly associated with the development of OW/OB and IGT/T2D, with higher incidence rates in adults reporting a reduction in standing time at follow-up. However, the associations became non-significant after adjustment for covariates, especially total annual family income and submaximal working capacity (data not shown).

\section{Discussion}

Overall, we observed that greater amounts of occupational standing time are associated with a lower incidence of OW/OB and IGT/T2D in this sample of adults. However, greater time spent standing was not sufficient in and of itself to prevent the development of outcome measures. The addition of confounding factors to the models, especially annual income and cardiorespiratory fitness, led to non-significant associations. Thus, our results suggest that workplace standing time alone is not sufficient to prevent the incidence of OW/OB and IGT/ T2D. Future efforts are needed to better understand the added value of standing time for overall health.

Sitting has become pervasive in today's environment [30-32] and studies have provided compelling evidence that excessive sitting is associated with the development of several chronic diseases and premature mortality $[2,5,19]$. Recent intervention studies suggest that replacing sitting with standing may result in rapid and positive changes in important health markers $[20,21,33]$. For example, Buckley et al. compared the impact of an afternoon of seated vs. standing office work in a group of 10 adults [20]. In comparison to the seated condition, they reported that participants burned $174 \mathrm{kcal}$ more during the standing condition, and also demonstrated a $43 \%$ lower glycemic response following a test meal. Similarly, Thorp et al. reported that alternating between sitting and standing every 30 minutes resulted in an $11 \%$ lower glycemic response to a test meal, when compared to a typical (e.g. sitting) workstation [21]. These intervention studies are supported by the recent paper of 


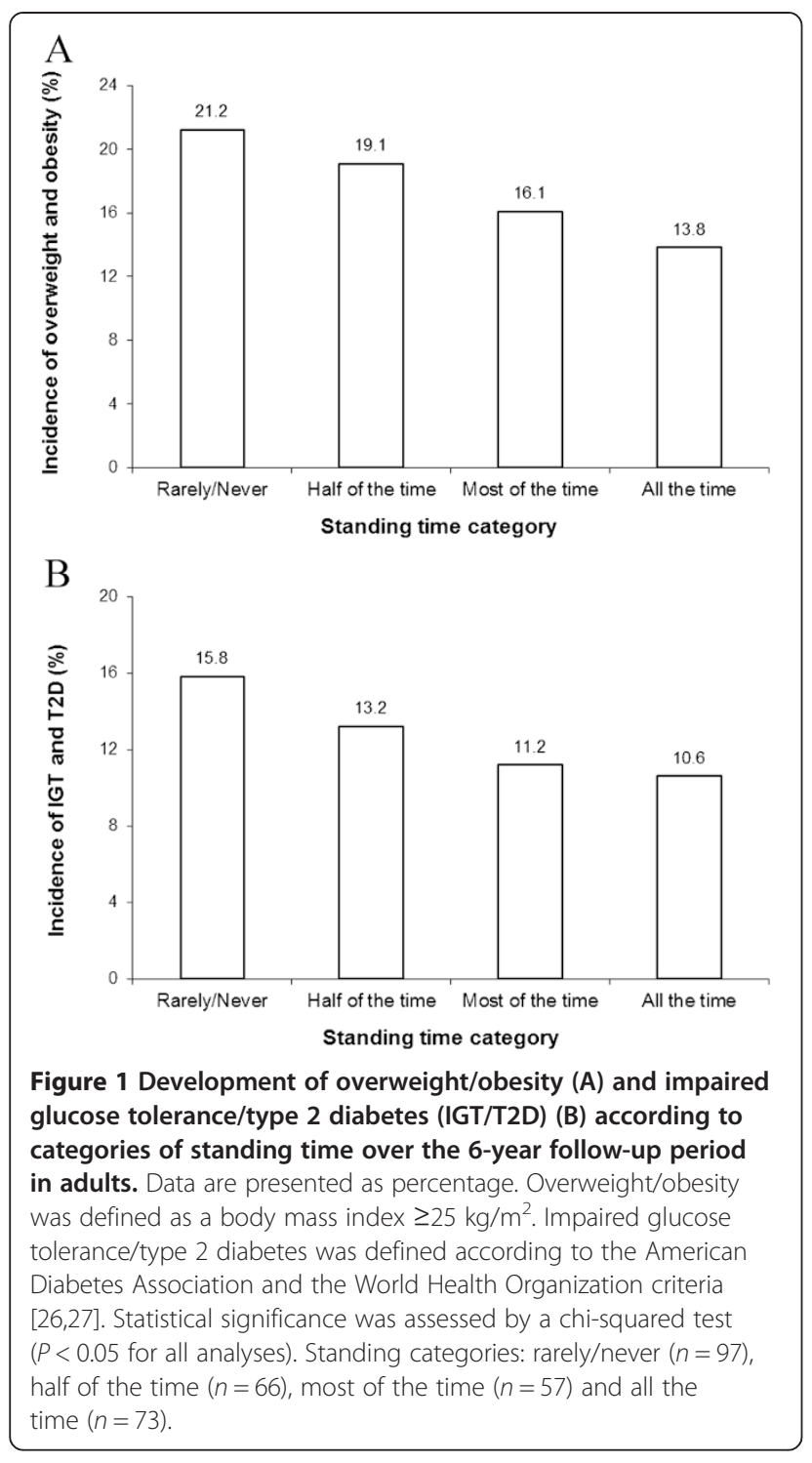

Table 2 Risk for the incidence of overweight/obesity and impaired glucose tolerance/type 2 diabetes by standing time category over the 6-year follow-up period

\begin{tabular}{|c|c|c|c|c|c|}
\hline & $\begin{array}{l}\text { Rarely/Never } \\
(n=97)\end{array}$ & $\begin{array}{l}\text { Half of the time } \\
(n=66)\end{array}$ & $\begin{array}{l}\text { Most of the time } \\
(n=57)\end{array}$ & $\begin{array}{l}\text { All the time } \\
(n=73)\end{array}$ & $P$ for trend \\
\hline \multicolumn{6}{|l|}{ Overweight/obesity } \\
\hline Age- and sex-adjusted OR (95\% Cl) & 1.00 & $0.94(0.53-1.48)$ & $0.79(0.34-1.44)$ & $0.63(0.21-1.22)$ & $<0.05$ \\
\hline Multivariable-adjusted OR ${ }^{a}(95 \% \mathrm{Cl})$ & 1.00 & $0.97(0.55-1.51)$ & $0.88(0.42-1.57)$ & $0.85(0.31-1.37)$ & 0.19 \\
\hline \multicolumn{6}{|c|}{ Impaired glucose tolerance/type 2 diabetes } \\
\hline Age- and sex-adjusted OR (95\% Cl) & 1.00 & $0.91(0.47-1.49)$ & $0.80(0.31-1.53)$ & $0.66(0.22-1.27)$ & $<0.05$ \\
\hline Multivariable-adjusted OR ${ }^{a}$ (95\% Cl) & 1.00 & $0.96(0.51-1.53)$ & $0.90(0.40-1.65)$ & $0.91(0.35-1.49)$ & 0.36 \\
\hline
\end{tabular}

adjusted for age, sex, smoking habits, total annual family income, daily caloric intake, and submaximal working capacity. Overweight/obesity was defined as a body mass index $\geq 25 \mathrm{~kg} / \mathrm{m}^{2}$. Impaired glucose tolerance/type 2 diabetes was defined according to the American Diabetes Association and the World Health Organization criteria $[26,27]$. Abbreviations: OR odds ratio, $\mathrm{Cl}$ confidence interval.
Katzmarzyk, who found that time spent standing was inversely associated with mortality risk [19]. Although standing appears to be a better choice than sitting for cardio-metabolic health, results of the present study suggest that other important factors should be considered (e.g. annual income and cardiorespiratory fitness) to ultimately prevent the development of chronic diseases.

The definition of standing time in the present study (i.e. time spent standing at work or during the main occupation) suggests that participants are probably not only standing still; light-intensity physical activity may also be involved in this amount of time spent standing. There is a growing body of evidence to suggest that light-intensity physical activity (e.g. walking) confers health benefits $[16,34,35]$. Although light-intensity physical activity is not typically part of physical activity guidelines, important health benefits can certainly be obtained at the lower end of the energy expenditure continuum [8].

There are a number of biological mechanisms through which greater time spent standing may lead to a reduced risk of chronic diseases. Standing may have a measurable impact on important metabolic processes, especially those related to glycemic control and lipoprotein metabolism. In comparison to a day of prolonged sitting, Latouche et al. showed that a day which incorporates light intensity activity breaks results in increased expression of genes related to lipid and carbohydrate metabolism in skeletal muscle [36]. Similarly, Hamilton et al. reported that standing results in large increases in lipoprotein lipase activity when compared to prolonged sedentary behavior in animal models [37]. In addition to any direct metabolic impact, standing may also be associated with reduced weight gain by slightly but consistently increasing energy expenditure, as suggested by the results of Buckley et al. [20].

There are several strengths and limitations of this study that warrant discussion. Strengths of this study include its longitudinal design and the adjustment for 

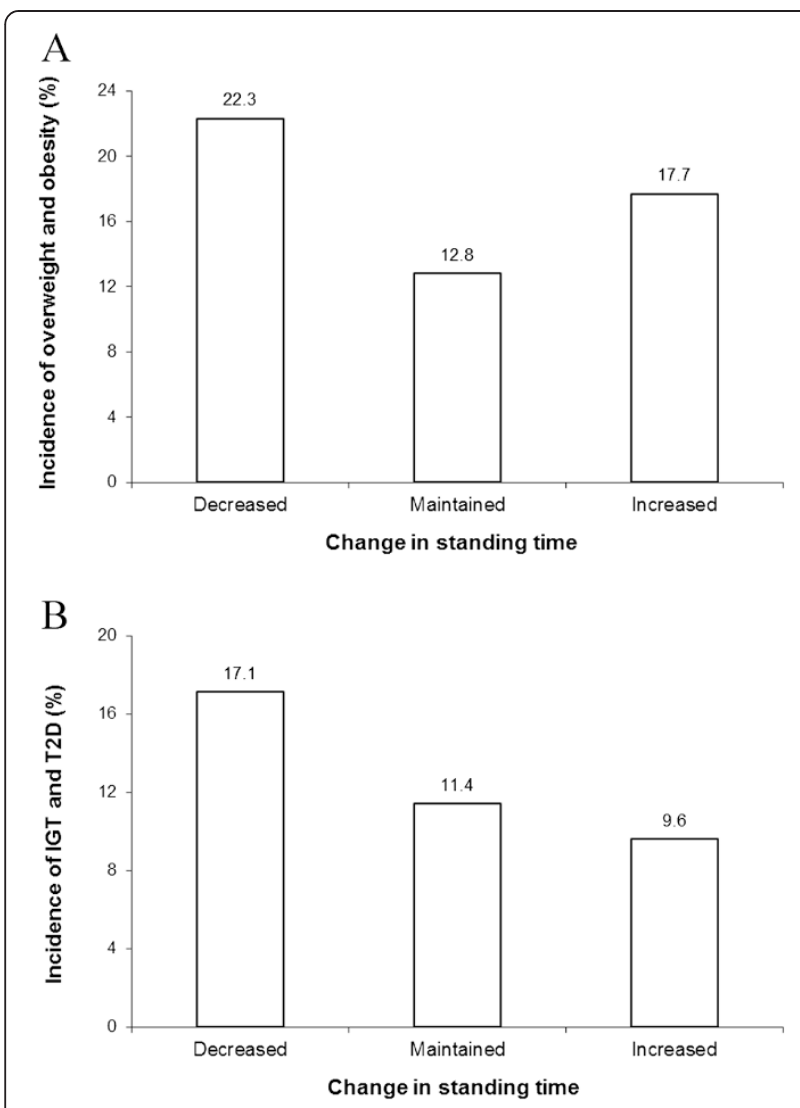

Figure 2 Development of overweight/obesity (A) and impaired glucose tolerance/type 2 diabetes (IGT/T2D) (B) according to changes in standing time over the 6-year follow-up period in adults. Data are presented as percentage. Overweight/obesity was defined as a body mass index $\geq 25 \mathrm{~kg} / \mathrm{m}^{2}$. Impaired glucose tolerance/type 2 diabetes was defined according to the American Diabetes Association and the World Health Organization criteria $[26,27]$. Statistical significance was assessed by a chi-squared test $(P<0.05$ for all analyses). Change in standing time categories: decreased $(n=82)$, maintained $(n=149)$ and increased $(n=62)$.

important variables that could confound the relationship between standing time and the incidence of chronic diseases (e.g. caloric intake, cardiorespiratory fitness and socioeconomic status). Furthermore, data were obtained from both men and women and we used an approach that should minimize confounding with repeated measures (baseline and year 6). However, our results need to be interpreted in light of the following limitations. First, the relatively small sample size limits statistical power and more high quality and well powered studies are needed to better appreciate the influence of standing time on the development of chronic diseases. The present study should thus be seen as an exploratory analysis which needs to be replicated in larger cohorts. Second, the exposure variable (standing time) was selfreported from a questionnaire and its validity is uncertain. Our findings are also limited to occupational standing, as opposed to total standing time. Third, the level of movement/activity while standing was not known and some people may have been more active than others during this period. Fourth, the external generalizability of our findings may be restricted to adults of Western European descent. Finally, the possibility of residual confounding by unmeasured variables is always a possibility in observational studies.

\section{Conclusions}

In summary, the present study is the first to examine the association between occupational standing time and the incidence of OW/OB and IGT/T2D in adults. Our results suggest that standing time alone is not sufficient to prevent the incidence of OW/OB and IGT/ T2D, which has implication for the risk of other chronic diseases. Replication studies with longer follow-up periods and larger sample sizes are needed to better understand the potential benefits of higher amounts of standing time throughout the day on the prevention of chronic diseases.

\section{Competing interests}

The authors declare that they have no competing interests.

\section{Authors' contributions}

JPC designed the study, conducted the analyses, and wrote the manuscript TJS helped to write the manuscript. JPC, TJS, MST, PTK, AT and CB contributed to the interpretation of data and revised the paper critically for important intellectual content. CB created the Quebec Family Study. All authors read and approved the final manuscript.

\section{Acknowledgements}

We express our gratitude to the subjects for their participation in the Quebec Family Study and the staff of the Physical Activity Sciences Laboratory at Laval University for their contribution to this study. We especially thank Dr. Germain Thériault, Guy Fournier, Monique Chagnon, Lucie Allard, and Claude Leblanc for their help in the collection and analysis of the data. The authors acknowledge the financial support over 20 years of the Medical Research Council of Canada (now the Canadian Institutes of Health Research) through several grants for the Quebec Family Study as well as other agencies from the governments of Quebec and Canada. JPC holds a Junior Research Chair in Healthy Active Living and Obesity Research. TJS is supported by a postdoctoral fellowship from the Heart and Stroke Foundation of Canada. PTK holds the Marie Edana Corcoran Endowed Chair in Pediatric Obesity and Diabetes. AT holds a Canada Research Chair in Environment and Energy Balance. CB is partially supported by the John W. Barton Sr. Chair in Genetics and Nutrition.

\section{Author details}

${ }^{1}$ Healthy Active Living and Obesity Research Group, Children's Hospital of Eastern Ontario Research Institute, 401 Smyth Road, Ottawa, ON K1H 8L1, Canada. ${ }^{2}$ Department of Applied Human Sciences, Faculty of Science, University of Prince Edward Island, 550 University Ave, Charlottetown, PE C1A 4P3, Canada. ${ }^{3}$ Physical Activity and Obesity Epidemiology Laboratory, Pennington Biomedical Research Center, 6400 Perkins Road, Baton Rouge, LA 70808-4124, USA. ${ }^{4}$ Department of Kinesiology, Faculty of Medicine, 2300 de la Terrasse, Laval University, Quebec City, QC G1V 0A6, Canada. ${ }^{5}$ Human Genomics Laboratory, Pennington Biomedical Research Center, 6400 Perkins Road, Baton Rouge, LA 70808-4124, USA.

Received: 24 September 2014 Accepted: 5 January 2015

Published online: 10 February 2015 


\section{References}

1. Saunders TJ, Tremblay MS, Després JP, Bouchard C, Tremblay A, Chaput JP. Sedentary behaviour, visceral fat accumulation and cardiometabolic risk in adults: a 6-year longitudinal study from the Quebec Family Study. PLoS One. 2013;8:e54225.

2. Wilmot EG, Edwardson CL, Achana FA, Davies MJ, Gorely T, Gray LJ, et al. Sedentary time in adults and the association with diabetes, cardiovascular disease and death: systematic review and meta-analysis. Diabetologia. 2012;55:2895-905

3. Saunders TJ, Larouche R, Colley RC, Tremblay MS. Acute sedentary behaviour and markers of cardiometabolic risk: a systematic review of intervention studies. J Nutr Metab. 2012;2012:712435.

4. Grontved A, Hu FB. Television viewing and risk of type 2 diabetes, cardiovascular disease, and all-cause mortality: a meta-analysis. JAMA. 2011;305:2448-55

5. Thorp AA, Owen N, Neuhaus M, Dunstan DW. Sedentary behaviors and subsequent health outcomes in adults: a systematic review of longitudinal studies, 1996-2011. Am J Prev Med. 2011;41:207-15.

6. Saunders TJ, Chaput JP, Tremblay MS. Sedentary behaviour as an emerging risk factor for cardiometabolic diseases in children and youth. Can J Diabetes. 2014;38:53-61.

7. Edwardson CL, Gorely T, Davies MJ, Gray LJ, Khunti K, Wilmot EG, et al. Association of sedentary behaviour with metabolic syndrome: a meta-analysis. PLoS One. 2012; 7:e34916.

8. Tremblay MS, Colley RC, Saunders TJ, Healy GN, Owen N. Physiological and health implications of a sedentary lifestyle. Appl Physiol Nutr Metab. 2010;35:725-40.

9. Heinonen I, Helajärvi H, Pahkala K, Heinonen OJ, Hirvensalo M, Pälve K, et al. Sedentary behaviours and obesity in adults: the cardiovascular risk in young Finns study. BMJ Open. 2013;3:e002901.

10. Chaput JP, Saunders TJ, Mathieu MĖ, Henderson M, Tremblay MS, O'Loughlin J, et al. Combined associations between moderate to vigorous physical activity and sedentary behaviour with cardiometabolic risk factors in children. Appl Physiol Nutr Metab. 2013;38:477-83.

11. Biddle SJ, King J, Yates T. TV viewing, but not total sedentary behaviour, is associated with adverse cardiometabolic biomarkers in adolescents. Evid Based Nurs. 2012;15:113-4.

12. Stamatakis E, Hamer M, Dunstan DW. Screen-based entertainment time, all-cause mortality, and cardiovascular events: population-based study with ongoing mortality and hospital events follow-up. J Am Coll Cardiol. 2011:57:292-9.

13. Carson V, Wong SL, Winkler E, Healy GN, Colley RC, Tremblay MS. Patterns of sedentary time and cardiometabolic risk among Canadian adults. Prev Med. 2014;65C:23-7.

14. Saunders TJ, Tremblay MS, Mathieu MË, Henderson M, O'Loughlin J, Tremblay A, et al. Associations of sedentary behavior, sedentary bouts and breaks in sedentary time with cardiometabolic risk in children with a family history of obesity. PLoS One. 2013;8:e79143.

15. Peddie MC, Bone JL, Rehrer NJ, Skeaff CM, Gray AR, Perry TL. Breaking prolonged sitting reduces postprandial glycemia in healthy, normal-weight adults: a randomized crossover trial. Am J Clin Nutr. 2013:98:358-66.

16. Dunstan DW, Kingwell BA, Larsen R, Healy GN, Cerin E, Hamilton MT, et al. Breaking up prolonged sitting reduces postprandial glucose and insulin responses. Diabetes Care. 2012;35:976-83.

17. Healy GN, Matthews CE, Dunstan DW, Winkler EA, Owen N. Sedentary time and cardio-metabolic biomarkers in US adults: NHANES 2003-06. Eur Heart J. 2011;32:590-7

18. Healy GN, Dunstan DW, Salmon J, Cerin E, Shaw JE, Zimmet PZ, et al. Breaks in sedentary time: beneficial associations with metabolic risk. Diabetes Care. 2008:31:661-6.

19. Katzmarzyk PT. Standing and mortality in a prospective cohort of Canadian adults. Med Sci Sports Exerc. 2014:46:940-6.

20. Buckley JP, Mellor DD, Morris M, Joseph F. Standing-based office work shows encouraging signs of attenuating post-prandial glycaemic excursion. Occup Environ Med. 2014;71:109-11.

21. Thorp AA, Kingwell BA, Sethi P, Hammond L, Owen N, Dunstan DW. Alternating bouts of sitting and standing attenuates postprandial glucose responses. Med Sci Sports Exerc. 2014;46:2053-61.

22. Chaput JP, Pérusse L, Després JP, Tremblay A, Bouchard C. Findings from the Quebec family study on the etiology of obesity: genetics and environmental highlights. Curr Obes Rep. 2014;3:54-66.
23. Bouchard C. Genetic epidemiology, association and sib-pair linkage: results from the Quebec Family Study. In: Bray G, Ryan D, editors. Molecular and Genetic Aspects of Obesity. Baton Rouge: Louisiana State University Press; 1996. p. 470-81.

24. The Airlie (VA) Consensus Conference: In Standardization of anthropometric measurements. Edited by Lohman TG, Roche AF, Martorell R. Champaign: Human Kinetics Publishers; 1988: 39-80.

25. Richterich R, Dauwwalder H. Zur bestimmung der plasmaglukose-konzentration mit der hexokinase-glucose-6-phosphat-deshydrogenase-methode. Schweiz Med Wochenschr. 1971;101:615-8.

26. American Diabetes Association. Report of the expert committee on the diagnosis and classification of diabetes mellitus. Diabetes Care. 1997:20:1183-97.

27. Alberti KG, Zimmet PZ. Definition, diagnosis and classification of diabetes mellitus and its complications, part 1: diagnosis and classification of diabetes mellitus provisional report of a WHO consultation. Diabet Med. 1998;15:539-53.

28. Tremblay A, Sévigny J, Leblanc C, Bouchard C. The reproducibility of a three-day dietary record. Nutr Res. 1983;3:819-30.

29. Bouchard C, Lortie G, Simoneau JA, Leblanc C, Thériault G, Tremblay A. Submaximal power output in adopted and biological siblings. Ann Hum Biol. 1984:11:303-9.

30. Bauman A, Ainsworth BE, Sallis JF, Hagströmer M, Craig CL, Bull FC, et al. The descriptive epidemiology of sitting: a 20-country comparison using the International Physical Activity Questionnaire (IPAQ). Am J Prev Med. 2011:41:228-35.

31. Harrington DM, Barreira TV, Staiano AE, Katzmarzyk PT. The descriptive epidemiology of sitting among US adults, NHANES 2009/2010. J Sci Med Sport. 2014;17:371-5

32. Matthews CE, Chen KY, Freedson PS, Buchowski MS, Beech BM, Pate RR, et al. Amount of time spent in sedentary behaviors in the United States, 2003-2004. Am J Epidemiol. 2008;167:875-81.

33. Stephens BR, Granados K, Zderic TW, Hamilton MT, Braun B. Effects of 1 day of inactivity on insulin action in healthy men and women: interaction with energy intake. Metabolism. 2011;60:941-9.

34. Kim J, Tanabe K, Yokoyama N, Zempo H, Kuno S. Objectively measured light-intensity lifestyle activity and sedentary time are independently associated with metabolic syndrome: a cross-sectional study of Japanese adults. Int J Behav Nutr Phys Act. 2013;10:30.

35. Buman MP, Winkler EA, Kurka JM, Hekler EB, Baldwin CM, Owen N, et al. Reallocating time to sleep, sedentary behaviors, or active behaviors: associations with cardiovascular disease risk biomarkers, NHANES 2005-2006. Am J Epidemiol. 2014;179:323-34.

36. Latouche C, Jowett JB, Carey AL, Bertovic DA, Owen N, Dunstan DW, et al. Effects of breaking up prolonged sitting on skeletal muscle gene expression. J Appl Physiol. 2013;114:453-60.

37. Hamilton MT, Hamilton DG, Zderic TW. Role of low energy expenditure and sitting in obesity, metabolic syndrome, type 2 diabetes, and cardiovascular disease. Diabetes. 2007;56:2655-67.

\section{Submit your next manuscript to BioMed Central and take full advantage of:}

- Convenient online submission

- Thorough peer review

- No space constraints or color figure charges

- Immediate publication on acceptance

- Inclusion in PubMed, CAS, Scopus and Google Scholar

- Research which is freely available for redistribution 